\title{
Proposta de um Modelo Organizacional a uma Microempresa Prestadora de Serviços - MOm
}

\author{
Proposal of an organizational model to a micro enterprise that provides services - \\ Omm
}

\author{
Roberta da Conceição António dos $\operatorname{Santos}^{1}$, Aline Dresch ${ }^{*}$, Douglas Rafael Veit ${ }^{1}$ \\ ${ }^{1}$ UNISINOS, Rio Grande do Sul, Brasil.
}

\section{INFO ARTIGO}

Palavras-chave:

Modelo organizacional, Estratégia de negócio, modelo microempresas, MOm.

\section{ARTICLE INFO}

\section{Keywords:}

Organizational model,

Business strategy,

Micro enterprise

model,

MOm.

\begin{abstract}
RESUMO
O modelo organizacional torna-se fundamental para as empresas acompanharem as constantes mudanças do mercado, independentemente do porte e ramo de atuação. Quanto menor a empresa, menor a importância dada a um modelo de gestão e mais ênfase aos processos operacionais. Diante deste contexto, propõe-se um modelo organizacional a uma microempresa prestadora de serviços, segundo conceitos do método da Design Science Research, possibilitando a criação de um artefato capaz de suprir os problemas apresentados. A base para a criação esteve no Modelo Canvas de Osterwalder e Pigneur, na Análise de Porter e no Modelo Estrela de Galbraith, Downey e Kates. Como resultado, é apresentado o Modelo Organizacional para a microempresa constituído pela definição da estratégia, estabelecimento da estrutura, promoção do negócio e conhecimento dos gastos, bem como o fundamento para a sua construção. O modelo contribui cientificamente por ser desenvolvido a partir de modelos tradicionais existentes, mas utilizando como abordagem metodológica a Design Science Research.
\end{abstract}

A B S T R A C T
The organizational model becomes essential for companies to keep up with
constant changes in the market, regardless of size and field of activity. The
smaller the company, the less importance is given to a management model
and more emphasis on operational processes. In this context, an
organizational model is proposed to a micro enterprise that provides services,
according to the concepts of Design Science Research method, enabling the
creation of an artifact capable of meeting the problems presented. The basis
for creation was in the Canvas Model by Osterwalder and Pigneur, in Porter's
Analysis and in the Star Model by Galbraith, Downey and Kates. As a result,
the Organizational Model for the micro enterprise is presented, consisting of
the definition of the strategy, establishment of the structure, promotion of the
business and knowledge of the expenses, as well as the foundation for its
construction. The evaluation was conducted through an interview and
questionnaire and it was found that the problems presented are common to
companies of the same size and the utility of the items presented in the
model.
model.

\footnotetext{
* Correspondência para autor: sanydasao@hotmail.com (dos Santos, R.C.A.), aldresch@unisinos.br (Aline, D.), douglasveit@unisinos.br (Veit, D. R.).
} 


\section{Introdução}

A definição da estratégia representa uma vantagem competitiva para a organização e deve partir de dentro para fora, isto é, deve considerar a estrutura da empresa, seus produtos e serviços oferecidos, concorrência e demanda de mercado (LEITE; PORSSE, 2003). Um bom planejamento estratégico melhora o trabalho da organização tanto no cumprimento de metas previamente estabelecidas quanto no desempenho de suas atividades. (BRUGNOLO FILHO; LUDOVICO, 2018; FIDDLER, 2007).

Independentemente do porte da empresa, é importante que as organizações adotem ferramentas e técnicas ou desenvolvam modelos de gestão adequados às atividades que exercem. Este modelo, muitas vezes, é resultado de valores que os líderes adquirem com o passar do tempo e de como estes encaram determinada situação (SENA, 2016). De acordo com Harper (2016), os bons gestores precisam ter a capacidade de preparar-se para acontecimentos futuros, reduzindo problemas e agindo rapidamente quando estes ocorrem.

As melhorias nas práticas organizacionais correspondem à implementação de ferramentas que mensurem não apenas a funcionalidade do sistema, mas que garantam o cumprimento de metas organizacionais (CRAIG; MOORES, 2005). As empresas podem ter uma estratégia definida e elaborada, mas nem sempre a executam. Este fato é justificado porque, frequentemente, o objetivo do gerente é confundido com o objetivo da organização e não há uma conexão com as funções e prioridades da mesma. (KAPLAN; NORTON, 2005).

A estruturação de um plano de negócios é crucial para que a organização se estabeleça, cumpra as metas estabelecidas e sobreviva mantendo o negócio no caminho desejado (BRUGNOLO FILHO; LUDOVICO, 2018; MEDEIROS, 2019). De acordo com Medeiros (2019), a partir deste plano é possível desenhar o caminho que se deseja seguir, o cenário a que a empresa está inserida, analisar a concorrência, bem como projetar investimentos necessários.

De acordo com Sena (2016), a fragilidade de não ter um modelo de gestão é facilmente observada em micro e pequenas empresas, pois operam com escassez de recursos e em um ambiente facilmente abalado. Segundo este autor, comumente, são empresas estabelecidas com base nas qualificações técnicas e operacionais dos criadores, com pouca experiência em gestão, e cujos processos não são estruturados segundo teorias e métodos científicos.

Além do modelo de gestão ser um guia para as organizações, é importante ser o mais atualizado possível, capaz de reagir a um ambiente de mudanças constantes que não são enfrentadas simplesmente com boas ideias de negócio (CHIAVENATO; SAPIRO, 2009; FIDDLER, 2007). Desta forma, o objetivo deste artigo é propor um modelo organizacional específico para microempresas e avaliá-lo em microempresas da região do Vale dos Sinos, no Rio Grande do Sul, testando a sua aplicabilidade em uma prestadora de serviços, localizada na cidade de São Leopoldo, Rio Grande do Sul. As principais atividades da empresa em que o modelo será aplicado são a desinsetização de casas, apartamentos e condomínios, limpeza de caixa d'água e a limpeza de piscinas.

A formação da microempresa deu-se segundo o conhecimento operacional de um dos sócios, sem um estudo aprofundado de como fundar um negócio. Atualmente, a empresa cogita a possibilidade de desistir da última atividade, pois não consegue atender a sua demanda por falta de mão de obra capacitada. Assim sendo, pretende-se, a partir do mapeamento do estado atual, identificar as principais dificuldades existentes na sua gestão e apresentar elementos relevantes de um modelo organizacional capaz de suprir as mesmas.

O trabalho apresenta cinco seções textuais para além desta, como parte da sua estrutura. A seção 2 faz uma sondagem teórica em cima de três ferramentas de gestão existentes. A seção 3 apresenta os procedimentos metodológicos seguidos para o desenvolvimento do artigo. $\mathrm{Na}$ seção 4 , o artefato proposto é desenvolvido no contexto da organização em estudo. É feita uma avaliação do artefato desenvolvido, apresentada na seção 5, para verificar a sua efetividade no alcance dos objetivos traçados. Por fim, são apresentadas as considerações finais na seção 6, com limitações deste estudo e sugestões para pesquisas futuras.

\section{Referencial teórico}

O plano de negócio não garante o sucesso da organização, mas é um ponto de partida para estruturar as ideias, projetar o funcionamento e o valor para os clientes (MEDEIROS, 2019; RAYOL; MOREIRA, 2007). 
Uma empresa com um planejamento estratégico adequado tende a apresentar um bom desempenho de suas atividades. (PORTER, 1989).

Segundo Osterwalder e Pigneur (2011), o modelo de negócio pode ser alterado e deve responder às necessidades da organização usando as fases de mobilização, compreensão, design, implementação e gerenciamento para auxiliar os gestores a entender a razão da necessidade de um novo modelo ou alteração do existente. Este modelo permite não só uma visão global do estado atual da empresa, como também fazer projeções futuras e fornecer maior segurança quanto à ação dos agentes externos. (REIS, 2013).

O modelo organizacional compreende uma rede de relações que une elementos necessários para a criação de organizações capazes de realizar a sua estratégia (GALBRAITH; DOWNEY; KATES, 2011). Estratégia esta que, segundo Chiavenato e Sapiro (2009), delimita os critérios para a definição do plano de ação que sustenta o negócio a longo prazo e resulta em vantagem competitiva. Assim, são apresentados três modelos que auxiliam na configuração de negócios, de modo a visualizar a realidade na qual a empresa está inserida, a auxiliar na definição dos fluxos e processos necessários.

\subsection{Modelo de negócios Canvas}

Segundo Osterwalder e Pigneur (2011), o Modelo de Negócio Canvas é uma ferramenta que apresenta os principais componentes do modelo de negócio de uma empresa em nove blocos integrados. É ideal para novos negócios, visto que proporciona ao empreendedor a visualização das suas ideias e análise da viabilidade do negócio. (DORNELAS et al., 2015).

O modelo permite definir quais consumidores atender, o tipo de produto ou serviço a oferecer, os meios para fluir a comunicação e como se relacionar com os clientes (DORNELAS et al., 2015). Osterwalder e Pigneur (2011) dizem, ainda, que o modelo auxilia na identificação dos principais recursos necessários, principais ações e parceiros que irão contribuir para o funcionamento do negócio, ajuda na visualização da origem da receita e do que tem sido mais dispendioso para a organização.

\subsection{Análise segundo Porter}

Segundo Bicho e Baptista (2006), o Modelo de Porter auxilia na construção da estratégia de empresas de diferentes portes, independentemente do ramo de atuação. Para tanto, é feita a análise das cinco forças, nomeadamente, rivalidade entre concorrentes, poder de barganha dos fornecedores, ameaça de produtos substitutos, poder de barganha dos compradores e ameaça de novos entrantes. (BRUGNOLO FILHO; LUDOVICO, 2018).

Rivalidade entre concorrentes - para Brugnolo Filho e Ludovico (2018), quando se conhece os concorrentes e as vantagens que eles apresentam relativamente à sua empresa e às demais do mesmo setor, mais fácil conseguem-se estratégias para oferecer um produto ou serviço diferenciado. De acordo com Braga (2013), o desenvolvimento de boas estratégias para se diferenciar no mercado é uma excelente opção para se sobressair da concorrência.

Poder de barganha dos fornecedores - é comum de ocorrer quando existem poucos fornecedores na área ou para determinado tipo de produto, pois qualquer problema com estes impactará na empresa (CARLA, 2013). Adicionalmente, é aconselhado pesquisar e analisar todas as possibilidades de fornecedores disponíveis e ter mais de uma opção para eventuais problemas. (BRAGA, 2013; MEDEIROS, 2019).

Ameaça de produtos substitutos - não necessariamente estes produtos são fisicamente similares ao que a empresa oferece, mas podem atender as mesmas funções ou desempenhar funções semelhantes (BRUGNOLO FILHO; LUDOVICO, 2018). Segundo Braga (2013), o mercado constantemente globalizado deve tirar o empreendedor do comodismo e despertá-lo no sentido de que logo um produto pode ser substituído ou entrar em desuso.

Poder de barganha dos compradores - é a força imposta, normalmente, por clientes que compram em maior valor e/ou quantidade de produtos (BICHO; BAPTISTA, 2006). Estes impõem à satisfação de requisitos especiais, como produtos ou serviços exclusivos, exigência de mais opções de pagamento, ocasionando, às vezes, em redução do preço. (BRAGA, 2013). 
Ameaça de novos entrantes - de acordo com Brugnolo Filho e Ludovico (2018), as empresas precisam criar mecanismos para dificultar a entrada de concorrentes no mercado. Devem aplicar esforços em determinados pontos para defender a sua marca, assegurar a qualidade do serviço oferecido, ser um diferencial e fidelizar os seus clientes. (PORTER, 1989).

\subsection{Modelo Estrela}

De acordo com Galbraith, Downey e Kates (2011), o Modelo Estrela surge na possibilidade de unir os componentes que as organizações precisam para o alcance da sua estratégia. Este modelo apresenta cinco componentes em suas extremidades, nomeadamente, estratégia, estrutura, processos, sistema de recompensa e sistema de pessoas, os quais devem estar conectados para que a organização consiga trabalhar em prol do seu objetivo. (GALBRAITH; DOWNEY; KATES, 2011).

Estratégia - segundo Galbraith, Downey e Kates (2011), a estratégia define a razão de ser da empresa e dela fazem parte a missão, visão, metas, o segmento de atuação e o público alvo. Marcondes (2015) diz que a estratégia deve ser clara e ter objetivos bem definidos, pois é a partir dela que são traçados os demais pontos para o alcance dos objetivos da organização.

Estrutura - para Galbraith, Downey e Kates (2011), mostra o funcionamento da empresa e organiza as partes em níveis, deixando suas funções e formas de relacionamento visíveis. De acordo aos mesmos autores, este funcionamento leva a empresa ao alcance da sua estratégia.

Processos e a Competência lateral - Bravo e Bilangieri (2006) dizem que independentemente da estrutura que a organização adote, mecanismos devem ser criados para que as informações fluam por todos os pontos de interesse. Este processo permite uma maior flexibilidade, rápidas respostas e a reunião das pessoas certas para agir frente às dificuldades. (GALBRAITH; DOWNEY; KATES, 2011).

Sistemas de recompensa - conforme Galbraith, Downey e Kates (2011), é importante que o esforço e a qualidade das tarefas dos trabalhadores sejam reconhecidos, motivando-os e impulsionando-os a melhoria contínua com relação às suas atividades. Carvalho et. al (2012) dizem que os diversos tipos de recompensas atribuídas aos trabalhadores para o comprimento e reconhecimento em relação às funções e ao trabalho realizado, convergem para uma maior produtividade da organização.

Sistema de pessoas - para Xavier (2011), este sistema transforma os funcionários para que as suas ações sejam voltadas ao desenvolvimento da organização. As pessoas são o principal ponto de interesse para o alcance da estratégia da organização e, por isso, devem ser bem selecionadas e preparadas para o bom desempenho das suas atividades. (SENA, 2014).

Ambos os modelos são importantes para empresas que pretendam desenvolver uma estratégia empresarial adequada ao mercado e podem ser usados de formas complementares. O Canvas tanto pode servir para a criação de um negócio, como para aprimorar um existente. Para uma empresa inserida no mercado, a Análise de Porter permite estudar a sua posição quanto aos parceiros e ao ambiente competitivo. O Modelo Estrela, por sua vez, define cinco principais e dependentes componentes que uma organização deve ter para realizar a sua estratégia.

De acordo com Vivas, Lippi e Silva (2013), um modelo não é chamado de melhor em relação ao outro, mas sim de mais adequado para determinada empresa. Adicionalmente, estes autores reforçam que a importância reside no fato de que os meios a serem estabelecidos sejam capazes de conduzir a organização a melhor decisão.

Assim, a partir do entendimento dos problemas da empresa em estudo e mediante a limitação de que os modelos apresentados não englobam todos os pontos de mudança requerida, pretende-se propor um modelo capaz de suprir as necessidades e apresentar melhores resultados para a organização. Para tanto, é utilizado o método da Design Science Research, cujo fim está no teste de novas ideias, com o intuito de beneficiar pessoas a partir da resolução de problemas que satisfaçam situações reais. (DRESCH; LACERDA; ANTUNES JÚNIOR, 2015). 


\section{Procedimentos Metodológicos}

Para atender ao objetivo desta pesquisa, foi utilizado o método de pesquisa da Design Science Research, que conforme Dresch, Lacerda e Antunes Jr. (2015), é um método de pesquisa que busca projetar soluções úteis para todo e qualquer contexto, inclusive na gestão, independentemente do tamanho da empresa, com auxílio na criação ou adaptação de artefatos para solucionar problemas. É, desta forma, um método que busca o rigor com a garantia de resultados confiáveis, e a relevância, no sentido de que o conhecimento gerado possa solucionar problemas reais (DRESCH; LACERDA; ANTUNES JÚNIOR, 2015).

O artefato modelado é o MOm, Modelo Organizacional para a microempresa, pertencente à classe de problemas de Análise de Problemas e Apoio à Tomada de Decisão, conforme indicado pelo método da Design Science Research. As pesquisas que utilizam a Design Science Research não buscam a generalização dos seus resultados em sentido teórico e geral, mas sim uma generalização para uma determinada classe de problemas (DRESCH; LACERDA; ANTUNES JÚNIOR, 2015). Sendo assim, os artefatos propostos, em uma determinada classe de problemas, podem ser utilizados, ainda que adaptados, por outros profissionais em contextos distintos, mas com problemas similares.

Os conceitos apresentados no Referencial Teórico são oriundos da Revisão Sistemática da Literatura. Esta Revisão Sistemática da Literatura é uma das primeiras etapas da Design Science Research e é realizada com o intuito de buscar soluções pré-existentes nas bases de conhecimento atuais (DRESCH; LACERDA; ANTUNES JÚNIOR, 2015). Assim, a partir das soluções encontradas, elas podem ser adaptadas ou modificadas, para resultar no desenvolvimento do artefato específico para a classe de problemas que está sendo endereçada.

Foram utilizadas diferentes técnicas para coleta de dados ao longo da pesquisa. Inicialmente, foi realizada a entrevista não estruturada, que segundo Dresch, Lacerda e Antunes Jr. (2015), capta as informações de maneira mais ampla. Nesta, o entrevistado falou ligeiramente dos serviços que a empresa oferece e de que maneira são gerenciados e priorizados. Foram comentadas, também, as limitações que a empresa vem enfrentando e as suas possíveis origens.

Em seguida, para uma melhor análise, um questionário com perguntas previamente elaboradas, onde observou-se que dentre os inúmeros problemas que a empresa enfrenta, seu gerente desconhece a necessidade de um modelo organizacional e de constante atualização quanto às mudanças de mercado. De acordo com Debois (2017), a escolha do uso do questionário para além de ter um custo baixo, é uma forma prática e rápida de obter dados sobre qualquer assunto. Dando seguimento ao método, utilizou-se o roteiro proposto pelo Design Science Research para a condução de pesquisas, apresentado no Quadro 1.

Quadro 1 - Roteiro de Trabalho Proposto pela DSR

\begin{tabular}{|c|c|c|c|}
\hline & Etapas da DSR & Método de trabalho & Saídas \\
\hline 1 & Identificação do problema & \multirow{2}{*}{$\begin{array}{l}\text { - Entrevista informal; proposição de } \\
\text { soluções aos problemas identificados. }\end{array}$} & \multirow[t]{2}{*}{ Problemas identificados. } \\
\hline 2 & Conscientização do Problema & & \\
\hline 3 & Revisão Sistemática da Literatura & $\begin{array}{l}\text { - Busca por referências segundo o } \\
\text { método da RSL. }\end{array}$ & $\begin{array}{l}\text { Correntes teóricas e } \\
\text { referencial da pesquisa. }\end{array}$ \\
\hline 4 & $\begin{array}{l}\text { Identificação dos artefatos e } \\
\text { configuração das classes de } \\
\text { problemas }\end{array}$ & $\begin{array}{l}\text { - Seleção dos possíveis artefatos para } \\
\text { a solução dos problemas } \\
\text { identificados. }\end{array}$ & $\begin{array}{l}\text { Artefatos selecionados e } \\
\text { explanados no referencial } \\
\text { teórico. }\end{array}$ \\
\hline 5 & $\begin{array}{c}\text { Proposição de artefatos para } \\
\text { resolver o problema }\end{array}$ & \multirow{2}{*}{$\begin{array}{l}\text { - Proposição e projeto do artefato que } \\
\text { melhor se enquadra ao problema; } \\
\text { análise de métodos do referencial. }\end{array}$} & \multirow[t]{2}{*}{$\begin{array}{l}\text { Exposição e detalhamento } \\
\text { do artefato proposto. }\end{array}$} \\
\hline 6 & Projeto do artefato selecionado & & \\
\hline 7 & Desenvolvimento do artefato & - Abordagem por meio de protótipo. & Artefato em estado \\
\hline
\end{tabular}




\begin{tabular}{|c|c|c|c|}
\hline & Etapas da DSR & Método de trabalho & Saídas \\
\hline & & & funcional. \\
\hline 8 & Avaliação do artefato & $\begin{array}{c}\text { - Questionário e entrevista; análise } \\
\text { dos resultados e proposição de } \\
\text { melhorias. }\end{array}$ & Opinião dos entrevistados. \\
\hline 9 & Explicitação das aprendizagens & \multirow{2}{*}{$\begin{array}{l}\text { - Apresentação dos resultados } \\
\text { obtidos; sugestões para estudos } \\
\text { futuros; exposição de limitações e } \\
\text { casos de sucesso. }\end{array}$} & \multirow[b]{2}{*}{$\begin{array}{c}\text { Conclusões e limitações do } \\
\text { estudo. }\end{array}$} \\
\hline 10 & Conclusões & & \\
\hline 11 & $\begin{array}{c}\text { Generalização para uma classe de } \\
\text { problemas }\end{array}$ & $\begin{array}{c}\text { - Artefato generalizado a uma classe } \\
\text { de problemas existente; divulgação } \\
\text { do estudo. }\end{array}$ & $\begin{array}{l}\text { Artefato de possível } \\
\text { utilização futura. }\end{array}$ \\
\hline 12 & Comunicação dos resultados & - Publicação do Artigo. & Artigo publicado. \\
\hline
\end{tabular}

Fonte: Adaptado de Dresch, Lacerda e Antunes Jr. (2015).

Este método de trabalho funciona como um roteiro de doze passos para a realização de pesquisas, onde a partir do problema identificado e com a ajuda de referências existentes na literatura, permite enquadrar o mesmo a uma determinada classe de problemas e identificar artefatos existentes. Com o artefato sugerido e desenvolvido, Dresch, Lacerda e Antunes Jr. (2015) dizem ser necessária a avaliação do mesmo para analisar a sua utilidade ao referido projeto, expondo, em seguida, as limitações e pontos de sucesso.

Apesar da aplicação/utilização do artefato em uma empresa específica, a avaliação do será realizada em dez empresas do mesmo porte por meio de questionário e entrevista, visto que, a ideia da generalização a uma classe de problemas, segundo Dresch, Lacerda e Antunes Jr. (2015), possibilita o acesso e aplicabilidade por outras organizações com problemas semelhantes. De forma complementar, Debois (2017) comenta que uma avaliação torna-se mais consistente quando dirigida a mais de uma pessoa ou empresa. Finalmente, aprendizagens serão explicitadas e sugestões de estudos futuros apresentadas para que o tema avance e sirva como ponto de partida para outros pesquisadores.

Assim, observando as dificuldades de gestão organizacional da empresa em estudo pensou-se em propor um modelo organizacional capaz de contribuir para melhorar a sua gestão, com a aplicação do método da Design Science Research. Para a empresa em estudo, a DSR resulta na construção e apresentação de um artefato hábil de solucionar os problemas, transformando-os em estados desejados. (DRESCH; LACERDA; ANTUNES JÚNIOR, 2015).

\section{Desenvolvimento do Artefato}

A empresa pertence a dois irmãos que também são a força de trabalho da mesma. Para além destes, possui uma secretária e um técnico em química que apenas é chamado quando necessário. Um dos sócios era funcionário de uma empresa do mesmo setor, mas, com o fechamento desta, optou por comprar os equipamentos juntamente com o seu irmão e juntos continuarem com o serviço, formando uma sociedade. Além da falta de pessoas capacitadas, o dinheiro não tem sido suficiente para cobrir os gastos da empresa por má gerência, e fraca distinção e separação dos diferentes tipos de gastos, pessoa física e pessoa jurídica.

A empresa possui problemas na base da sua construção, uma vez que foi constituída por oportunidade, sem um estudo de como fundar um negócio, desconhecimento da necessidade de utilização de um modelo e da formulação de um plano estratégico. Frente aos problemas descritos, a Figura 1 apresenta o modelo MOm, Modelo Organizacional para a microempresa. 
Figura 1 - MOm - Modelo Organizacional para a Microempresa

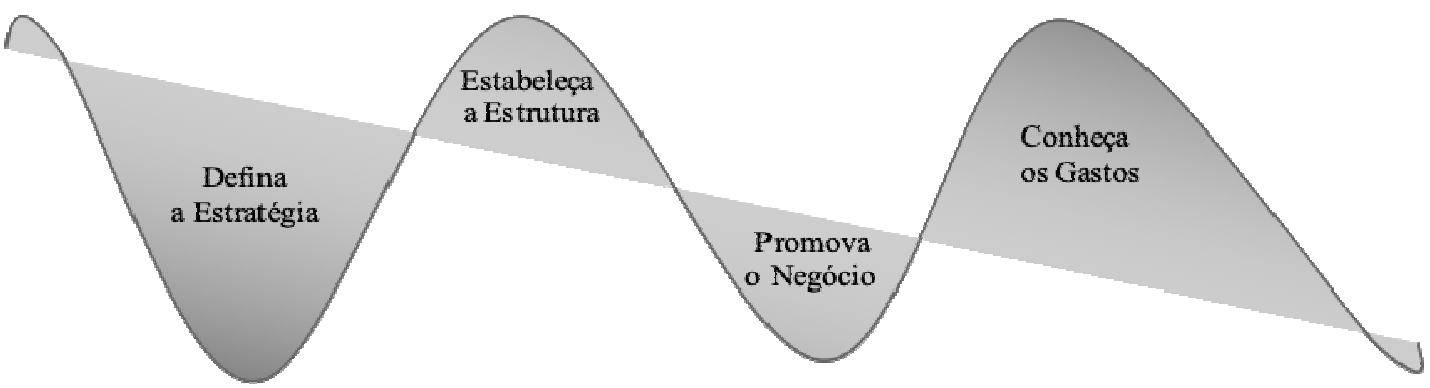

Fonte: elaborado pelos autores.

O modelo propõe a combinação de elementos, tendo como base os descritos no Referencial Teórico, a serem seguidos pela empresa para que se forme uma base sólida capaz de suportar a sua estrutura. Este foi construído a partir dos problemas evidenciados pela empresa em estudo e pela ausência de modelos que respondam às principais dificuldades enfrentadas pela mesma, cujo desdobramento é apresentado na Figura 2.

Figura 2 - MOm - Desdobramento do Modelo Organizacional para a Microempresa

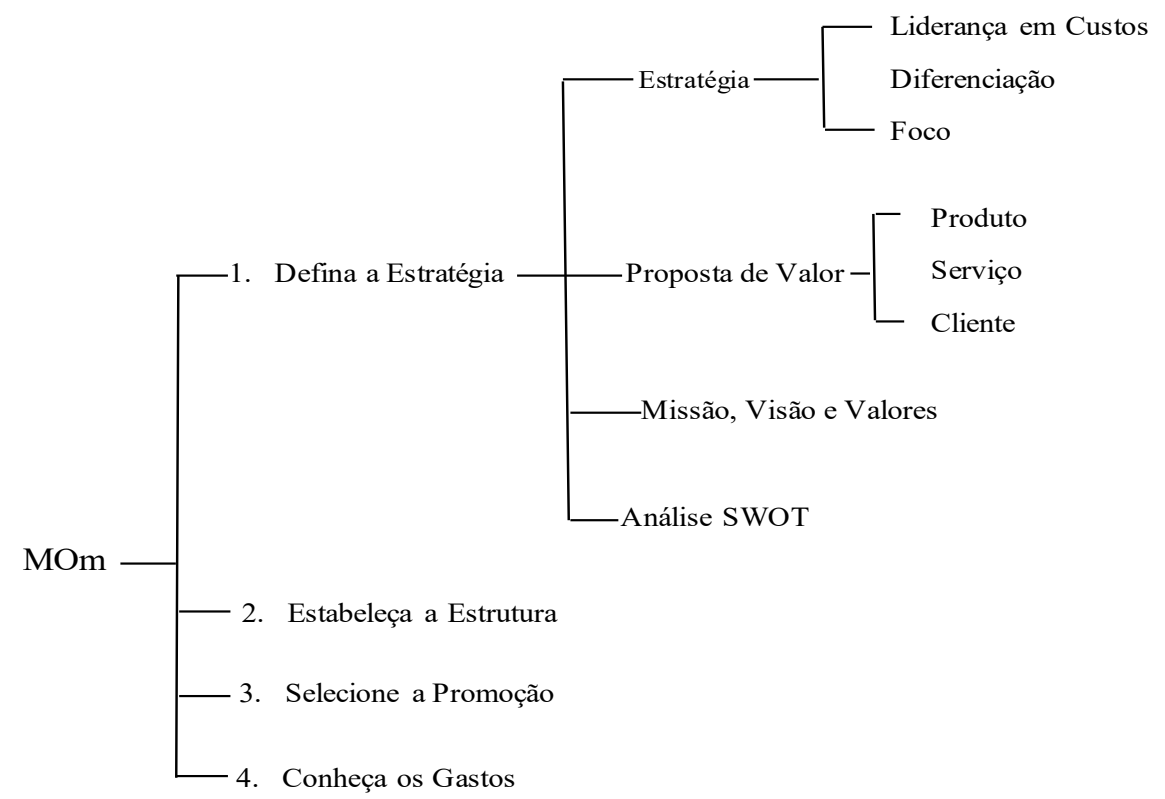

Fonte: elaborado pelos autores.

Ao contrário do que deveria ser, empresas deste porte costumam apresentar muitos problemas no que tange a sua organização. $\mathrm{O}$ artefato não apenas supre a necessidade de ter um modelo a ser consultado, como também foca nos pontos que representam os maiores problemas para a empresa, tornando-a mais competitiva. No primeiro instante, a empresa precisa definir a sua estratégia competitiva, direcionar a sua proposta de valor, definir a missão, visão e valores, e fazer a análise de cenários. Feito isto, estabelece a sua estrutura, seleciona a promoção que mais se adequa as suas atividades e conhece os gastos gerados para facilitar o controle financeiro da mesma.

\subsection{Defina a Estratégia}

Uma organização se destaca em um mercado competitivo ao diferenciar seus produtos e serviços dos de seus concorrentes. Assim, segundo Elaina (2012), dentre as estratégias genéricas de Porter as empresas podem optar pela liderança em custos, diferenciação e foco. 
A empresa que opta pela liderança em custo atrai seus clientes pelo preço, pois foca na redução de custos e despesas decorrentes do processo como um todo (PRATES, 2015). Para Elaina (2012), na estratégia de diferenciação, a empresa seleciona uma forma de se diferenciar no mercado, como por exemplo, em produtos e serviços, imagem, qualidade e suporte ao cliente. É uma estratégia que requer constante atualização e pesquisa de mercado para que o "diferencial" não seja ultrapassado.

A estratégia de foco define o nicho de atuação em parceria com a estratégia de liderança em custo ou diferenciação (GABRIEL, 2016). Para micro e pequenas empresas, a seleção de segmentos de atuação tornase mais assertiva por ter menos recursos humanos disponíveis, menos experiência de mercado, algumas vezes, e por mais facilmente conseguir manter o foco em suas operações. A estratégia de nicho geográfico precisa estar acompanhada de uma estratégia de expansão do negócio, pois o nicho pode saturar tanto pelo serviço quanto pela concorrência.

\subsubsection{Proposta de Valor}

Valor é uma variável medida pelo cliente que estimula o consumo de determinado bem ou serviço. Para Galbraith, Downey e Kates (2011), preposição de valor é um conjunto de diferenciais que as empresas optam em seus produtos, serviços ou clientes. Estes diferenciais fazem parte das estratégias competitivas de uma organização e são combinadas as estratégias genéricas de Porter. Desta forma, as empresas podem escolher valorizar seus produtos e/ou serviços, operações e clientes.

A empresa que se propõe a oferecer valor a seus clientes pelos produtos deve focar no desenvolvimento de novos produtos e/ou serviços ou, ainda, na melhoria dos já existentes que atendam às necessidades dos clientes (HERRERA, 2008). Esta proposta está intrinsecamente ligada à maneira como a empresa optou em se diferenciar do mercado. A proposição operações está ligada à estratégia de custo e de diferenciação, pois o foco é dar valor ao cliente em preço, qualidade e consistência nas operações (GALBRAITH; DOWNEY; KATES, 2011). Para as empresas que direcionam a sua proposta aos clientes, devem procurar atraí-los pela confiança e pelo bom relacionamento no decorrer do tempo. Está relacionada à estratégia de diferenciação pelo suporte, satisfação e rápidas soluções às necessidades dos clientes, por exemplo.

Desta forma, para a empresa em estudo, a sua estratégia competitiva está no nicho geográfico São Leopoldo, segmento de serviço de limpeza de piscinas, caixa d'água e desinsetização. A sua diferenciação é a qualidade e o suporte ao cliente, promovendo assistência técnica para qualquer eventualidade relacionada ao serviço prestado. A proposta de valor está direcionada às operações e ao cliente não apenas por ser uma prestadora de serviços, mas por ser atuante em um nicho que precisa primar pela qualidade de suas ofertas e manter seus clientes para permanecer no mercado.

\subsubsection{Definição da Missão, Visão e Valores}

Segundo Chiavenato e Sapiro (2009), a definição da missão, visão, valores, públicos de interesse e da proposta de valor, constituem a primeira e mais importante fase da estratégia organizacional. A missão pode ser considerada a personalidade da organização, a sua razão de ser tendo em vista a satisfação do ambiente externo. A sua definição deve fixar na atuação da empresa, valor que oferece hoje e no futuro, e para quem ela direciona seus esforços. (PAULA, 2015).

A visão representa o estado em que a empresa pretende chegar. Paula (2015) diz que a sua declaração deve ser pensada como uma projeção real, um desejo capaz de ser atingido e com foco bem definido para favorecer a todos os interessados. Os valores, por sua vez, definem um conjunto de princípios relacionados à comportamentos e decisões que guiam as pessoas envolvidas na empresa (BRUGNOLO FILHO; LUDOVICO, 2018). O Quadro 2 apresenta a missão, visão e valores sugeridos para a empresa em estudo.

Quadro 2 - Missão, Visão e Valores Sugeridos para a Empresa

Missão - Promover a qualidade $\quad$ Visão - Ser referência e reconhecida quanto à qualidade e confiabilidade na de vida de nossos clientes higienização e manutenção de caixas d'água, piscinas e no controle de através dos serviços prestados. pragas na região do Vale do Rio dos Sinos.

Valores - Qualidade, confiabilidade, responsabilidade socioambiental e transparência nos serviços prestados.

Fonte: Sugerido pelo Sócio 1 da empresa e autores. 
De acordo com Chiavenato e Sapiro (2009), estes pontos são flexíveis e alteráveis ao longo do tempo considerando a possibilidade e necessidade que a empresa terá em expandir o seu negócio para outro segmento ou outras localidades, a visão primeiramente definida não corresponderá ao estado futuro que a organização deseja alcançar. Ou ainda, supondo que o futuro delineado hoje seja atingido dentro de alguns anos, a estratégia deverá ser atualizada.

A empresa em estudo deve estar consciente de que existe para responder às necessidades e melhorar a qualidade de vida de seus clientes com a limpeza de caixas d'água e piscinas, mantendo-os livres de pragas. Ela ainda deve fazer uma projeção do futuro que pretende almejar, trilhando caminhos para alcançar o mesmo, primando pelo bom comportamento e atitude enquanto organização.

\subsubsection{Análise SWOT}

SWOT - do inglês Strenghts (forças), Weaknesses (fraquezas), Opportunities (oportunidades) e Threats (ameaças). É uma ferramenta utilizada para a construção de cenários que destaca o ambiente interno, que pode ser previsto e controlado pela empresa e o externo, que é incerto e fora do controle da mesma. Esta análise permite aprofundar o conhecimento sobre o ambiente corporativo, prevenindo a organização contra fatores negativos e explorando os positivos.

O objetivo é analisar no que e como os pontos positivos podem ser explorados a beneficiar a empresa e a minimizar danos que podem vir tanto de dentro quanto de fora da organização (CASAROTTO, 2016). Assim, do ambiente interno, forças são características que representam vantagens que a empresa possui internamente em relação à concorrência e fraquezas são características que representam desvantagens em relação à concorrência. Do ambiente externo, oportunidades são condições ou situações que a organização pode aproveitar em prol da sua estratégia competitiva e ameaças são situações ou condições que traduzem riscos a estratégia da organização.

Apesar das dificuldades enfrentadas pela empresa, esta ainda realiza a limpeza de piscinas e está analisando a possibilidade de adquirir o serviço de reconstrução de caixa d'água, pois possuem conhecimento e os clientes solicitam pela confiança nos serviços prestados. Porém, para que se torne viável, devem explorar os seus pontos positivos e minimizar ou eliminar os negativos, apresentados no Quadro 3.

Após a descrição da SWOT, é feita a análise pelo cruzamento do ambiente interno com o externo. Assim, as forças de qualidade nos serviços e de preços competitivos potencializam a oportunidade da empresa formar novas parcerias, bem como os funcionários treinados permitem que a empresa expanda o seu segmento de atuação. A qualidade nos serviços prestados e a assistência técnica protegem a empresa da ameaça contra a concorrência.

Quadro 3 - SWOT da Empresa

\begin{tabular}{|c|c|c|}
\hline & Positivo & Negativo \\
\hline 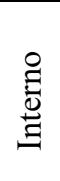 & $\begin{array}{l}\text { Forças } \\
\text { Qualidade nos serviços; funcionários } \\
\text { treinados; assistência técnica; preços } \\
\text { competitivos. }\end{array}$ & 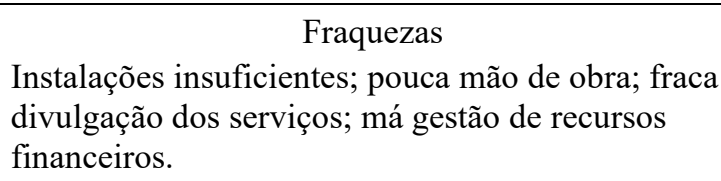 \\
\hline 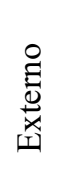 & $\begin{array}{l}\text { Oportunidades } \\
\text { Formação de novas parcerias; expansão do } \\
\text { segmento. }\end{array}$ & $\begin{array}{l}\text { Ameaças } \\
\text { Concorrência; recessão dos clientes; baixo } \\
\text { conhecimento da sociedade quanto à importância } \\
\text { destes serviços. }\end{array}$ \\
\hline
\end{tabular}

Fonte: Sugerido pelo Sócio 1 da empresa e autores.

As fraquezas de instalações insuficientes e pouca mão de obra inviabilizam a oportunidade da empresa formar novas parcerias, do mesmo modo que a fraca divulgação dos serviços dificulta a expansão do segmento. Não obstante, as fraquezas de instalações insuficientes e a pouca mão de obra, também, desprotegem a empresa contra a concorrência e, a fraca divulgação dos serviços impulsiona o baixo conhecimento da sociedade quanto à importância dos serviços prestados. 


\subsection{Estabeleça a Estrutura}

A estrutura reflete o tipo de organização, tipo de serviço ou produto oferecido, tamanho e maneira como tudo é atravessado internamente e deve ajudar a organização a realizar a estratégia existente (CHIAVENATO; SAPIRO, 2009; MINTZBERG; QUIM, 2001). Com base na estrutura percebe-se como as atividades estão divididas, as pessoas ou departamentos organizados e como os níveis estratégico, tático e operacional comunicam-se entre si. Estes níveis englobam as partes constituintes de uma organização que, segundo Mintzberg e Quim (2001), são o topo estratégico, a linha intermediária, a essência operacional, a tecnoestrutura, a staff de suporte e a ideologia que envolve toda uma organização.

Por ser uma microempresa, com possibilidade de expansão, ter uma característica jovem e dinâmica, é de acordo com Mintzberg e Quim (2001), uma organização empreendedora ou simples com uma estrutura de mais fácil controle. De acordo com a estrutura, os papéis organizacionais são distribuídos e, segundo Galbraith, Downey e Kates (2011), estes podem ser uma unidade de negócios, função ou algum cargo e, são definidos tendo em conta o resultado esperado e às responsabilidades atribuídas. Galbraith, Downey e Kates(2011) dizem ainda que qualquer organização requer pessoas aptas e capacitadas para realizar a sua estratégia.

Mesmo que cada um tenha o seu papel, deve haver comunicação e contato profissional para que haja colaboração na condução do trabalho, sem contar que muitas tarefas podem ser dependentes da execução de outras. Quanto menor a organização, mais saudável o fluxo de informações porque há contato direto entre todos os envolvidos.

Como a organização está com escassez de operadores é importante incluir um sistema de seleção e contratação de pessoas e treiná-las para desempenharem as suas devidas funções. Pelo seu tamanho, nicho que atende, dificuldade em visualizar e cobrir todos os gastos, e pelo fato de todos os serviços serem realizados em duplas, sugere-se que a organização tenha, no mínimo, duas duplas capacitadas para atender a todos os serviços, o que permite atender a dois clientes simultaneamente. Algumas vezes pode haver excesso de trabalho, outras ociosidade, mas com uma boa gestão, consegue-se balancear e atender aos clientes, cobrindo os gastos.

Por ser uma microempresa, a coordenação é direta, pois além do gerente instruir e coordenar a base na realização de suas tarefas, também faz parte da mesma base. De acordo com Mintzberg e Quim (2001), a organização precisa de um líder para estruturar o trabalho dos envolvidos e sempre que necessário participar na realização das tarefas. Desta forma, a organização terá na zona administrativa o sócio 1, que com a visão de toda empresa deve estar por dentro de cada passo a ser dado, analisar riscos e viabilidades e autorizar toda e qualquer ação antes da sua execução. A zona de vendas, regulamentação e marketing, VRM, ficará por conta da secretária, do químico e do sócio 1. A Figura 3 ilustra o organograma sugerido.

Figura 3 - Organograma Sugerido para a Empresa

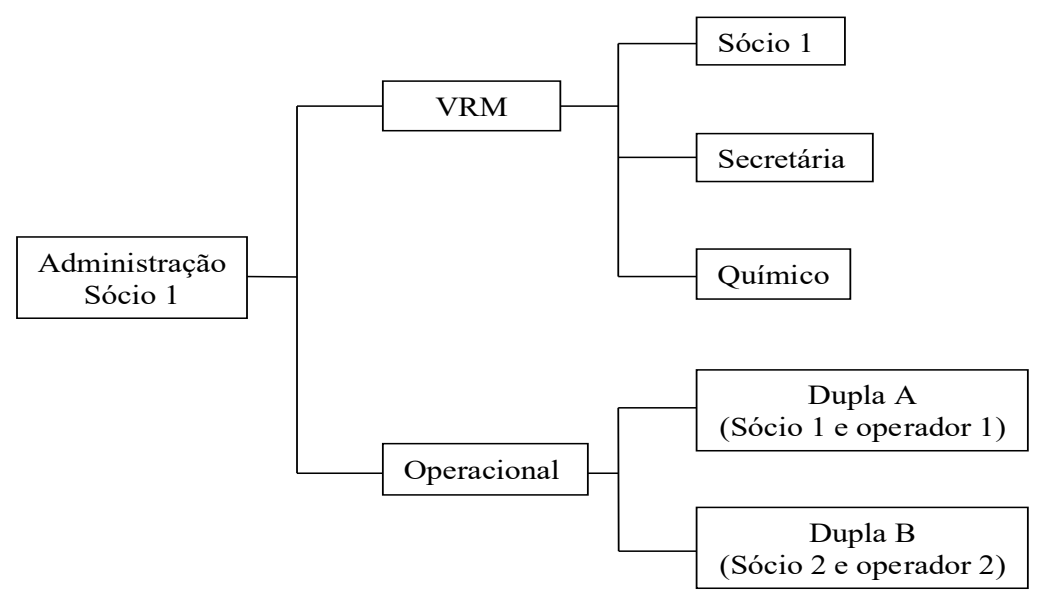

Fonte: Elaborado pelos autores. 
A secretária recebe as especificações do serviço, faz o orçamento com o cliente e, após a análise e aprovação do sócio 1, faz o agendamento. O químico é responsável pela análise de cada produto antes da sua utilização e pela assinatura dos laudos. O sócio 1 é responsável pelo marketing, contato com fornecedores e gerência dos gastos da empresa.

A zona operacional será formada por duas duplas, cada uma com treinamento suficiente para a realização de todos os serviços. A dupla A formada pelo sócio 1 e o operador 1 e a dupla B pelo sócio 2 e o operador 2.

\subsection{Selecione a Promoção}

A promoção de um produto ou serviço é uma forma de chamar a atenção, informar aos clientes sobre a sua existência e, muitas vezes, persuadi-los a compra. Medeiros (2019) diz que antes da adoção de uma estratégia, a empresa deve fazer uma seleção de onde e para quem deseja direcionar os seus esforços, depois estipular o que o cliente deve fazer para obter o benefício e, então, viabilizar os recursos necessários. Existem diversas formas de promover o negócio, dentre elas destacam-se a venda pessoal, telemarketing, propaganda, publicidade, promoção de venda, internet e políticas de fidelização. (GOMES, 2013).

A venda pessoal acontece quando o vendedor faz uma busca, seleciona e vai até ao público para o qual deseja atingir, fornece informações sobre a empresa e explica detalhes sobre os serviços oferecidos. No telemarketing faz-se o uso do telefone para entrar em contato com o cliente e procurar comercializar o produto ou serviço. O contato que o cliente faz para a empresa, por ligação telefónica, quer seja para solicitar informações, comprar ou reclamar de algum produto ou serviço, também é considerado telemarketing (MARTINS, 2016). Ambas permitem ao vendedor maior contato com os consumidores e um retorno rápido das suas ofertas.

A propaganda é anunciar a empresa, o produto ou o serviço por meio dos diferentes meios de comunicação, como jornais, revistas, rádio e televisão. Para Gomes (2013), o anúncio deve ser criativo, conter meios de contato e transmitir a mensagem desejada, destacando os benefícios do produto ou serviço oferecido. Contrariamente à propaganda, a publicidade também difunde as informações pelos meios de comunicação, mas gratuitamente.

Gomes (2013) diz que a promoção de venda fomenta as vendas em um curto espaço de tempo com descontos, sorteios e brindes, por exemplo. A internet, por sua vez, é uma forma de divulgação que pode permitir ao consumidor apenas o conhecimento da empresa e de seus produtos e serviços, como também a possível aquisição dos mesmos. Segundo Brugnolo Filho e Ludovico (2018), por ser facilmente acessada e ter um longo alcance, o seu uso ajuda a difundir o negócio e a aproximar mais dos clientes.

Para as optantes de políticas de fidelização, é importante conhecer e reter informações dos clientes, oferecendo promoções que mais se adequam aos interesses de cada um. Algumas empresas optam por cartões fidelidade, por exemplo, para que quando o cliente atinja determinado número de compras, ganhe algum desconto ou oferta. A Figura 4 ilustra um cartão de fidelidade sugerido para a empresa em estudo.

Figura 4 - Cartão de Fidelidade Sugerido para a Empresa
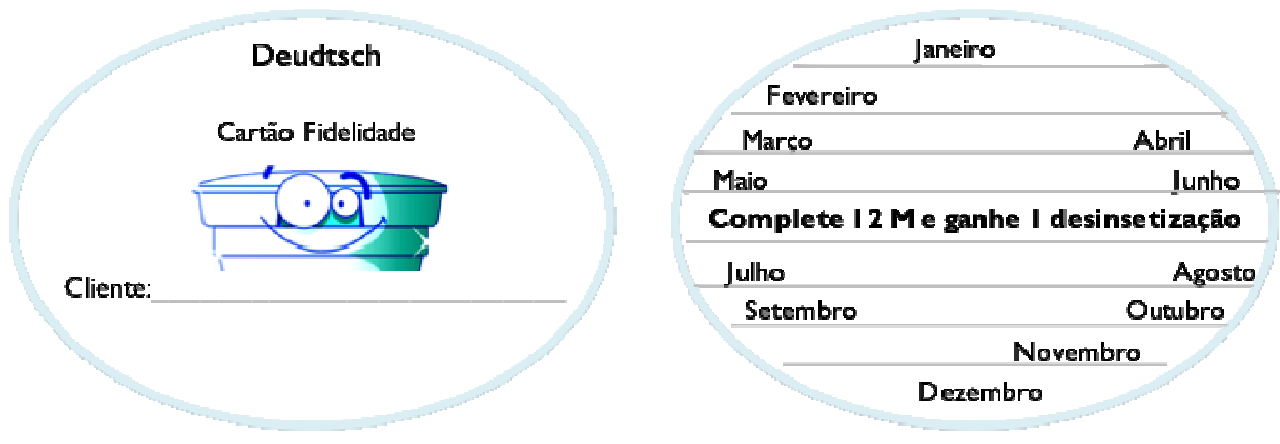

Fonte: Elaborado pelos autores.

Independentemente do tipo de promoção adotada, o importante é que esteja alinhada à estratégia da empresa, à posição, ao segmento, ao público de interesse e aos produtos e serviços oferecidos. Estas 
estratégias podem ser usadas tanto numa combinação de várias, como isoladamente. Algumas atraem um maior número de consumidores simultaneamente, outras requerem mais investimentos, e outras ainda proporcionam uma rápida resposta do consumidor. A escolha varia consoante o tipo de empresa e a estratégia adotada.

Para a empresa em estudo, as estratégias sugeridas são a internet, com a criação de uma página, por exemplo, contendo as informações dos serviços e contatos da empresa. No que tange à venda pessoal e telemarketing, a empresa tanto pode usar para atrair novos clientes, como para ir atrás dos que já foram, não apenas para tentar recapturá-los, mas para obter destes uma pesquisa de satisfação, saber as possíveis falhas que teve para que os mesmos optassem pelos seus concorrentes. Outra sugestão é a política de fidelização, a qual, por exemplo, ao fim de um ano de contrato de limpeza de piscinas pode ser ofertada uma desinsetização; ou ainda, após nove limpezas de caixa d'água, a décima sair pela metade do preço.

\subsection{Conheça os Gastos}

Assim como uma empresa precisa de uma boa estratégia, recursos humanos e processos bem definidos, ter o conhecimento de seus gastos auxilia no melhor gerenciamento e tomada de decisão. Este conhecimento permite, à empresa, o controle do que tem gastado com cada produto ou serviço, bem como para manter a sua própria estrutura. (LOBRIGATTI, 2004; LOGULHO, 2012).

De acordo com Bornia (2010), são considerados gastos os dispêndios que a empresa tem para adquirir um bem ou serviço. Estes aparecem na forma de custos e despesas. Custos são os gastos relativos à produção de um bem ou a prestação de um serviço, e despesas os que a empresa tem para manter a sua estrutura, não estando diretamente ligadas aos produtos ou serviços ofertados (LOGULHO, 2012). Ou seja, custo é o gasto com o que é oferecido ao cliente, seja na troca ou venda de mercadorias, e despesa o gasto para vender esta oferta sem considerar a produção ou a aquisição do material. (DAGOSTIM, 2010; LOGULHO, 2012).

Os custos dividem-se em diretos que são os mais fáceis de identificar por estarem diretamente ligados aos serviços e produtos, e indiretos de difícil identificação por não estarem diretamente relacionados aos produtos e serviços (BORNIA, 2010). Quanto à variação nos volumes de produção, tem-se os custos fixos que não alteram com o aumento ou diminuição da produção, custos variáveis que alteram consoante o nível de produção, despesas fixas que permanecem constantes independentemente da venda, e despesas variáveis que alteram consoante as vendas (SCHIER, 2013). O Quadro 4 apresenta os gastos da empresa em estudo.

Quadro 4 - Gastos da Empresa

\begin{tabular}{|l|l|}
\hline \multicolumn{1}{|c|}{ Custos de serviços } & \multicolumn{1}{c|}{ Despesas } \\
\hline - Mão de obra; & - Água e energia elétrica; \\
- Produtos usados nos serviços: material para limpeza & - Telefone e Internet; \\
de piscinas, limpeza de caixa d'água e desinsetização; & - Aluguel; \\
- Combustível; & - Salários: Pró-labore, Secretária e Químico; \\
-Depreciação dos equipamentos e do veículo; & - Promoções; \\
-Manutenção dos equipamentos e do veículo. & - Carro e combustível; \\
& - Material de limpeza e de escritório. \\
& \\
\hline
\end{tabular}

Fonte: Sugerido pelo Sócio 1 da empresa e autores.

Considera-se que uma empresa de serviços apenas tem custo quando presta algum serviço, sendo estes os gastos com a mão de obra e com o material utilizado. Para o caso da empresa em estudo, que oferece três serviços distintos e cada um requer um produto e tempo diferente para a sua execução, os serviços possuem custos distintos. As despesas não influenciam diretamente na realização dos serviços, mas viabilizam o bom funcionamento da empresa como um todo. 


\subsubsection{Salário dos Sócios}

Um fato muito comum em micro e pequenas empresas é a dificuldade em distinguir o lucro da empresa do salário do dono, sócio ou investidor e, ainda, confundir os gastos da empresa com os gastos pessoais. Os sócios de uma empresa podem ser remunerados pelo pró-labore e pela distribuição dos lucros (ALVES, 2012; FREITAS, 2018). O pró-labore é o salário do sócio que trabalha na empresa e a distribuição dos lucros é a remuneração que o sócio recebe quer trabalhe ou não, como uma forma de retorno pelo investimento. (FREITAS, 2018).

Freitas (2018) enuncia que o pró-labore deve ser definido tendo em conta a atividade realizada e a capacidade que a empresa tem em remunerar, e não quanto o dono ou sócio pretende ganhar. Para os sócios desta empresa, caso a mesma gere lucro, os seus salários serão o pró-labore adicionado à remuneração dos lucros. Esta remuneração é feita segundo regras definidas pelos acionistas sobre o percentual de cada sócio, periodicidade da distribuição e valor a ser deixado como reserva da empresa, por exemplo. (ALVES, 2012; FREITAS, 2018).

É importante separar a conta bancária da pessoa física a da pessoa jurídica e, haver rigor e competência para que os gastos pessoais saiam do salário ou da remuneração e, os da empresa, dos recursos que a própria gerar. Pouco ou nada adianta oferecer um excelente serviço, bom atendimento e ter seus clientes satisfeitos, se a empresa possui uma má gestão financeira. Em questão de tempo estará em decadência e não conseguirá manter a sua estrutura.

\subsection{Avaliação do Artefato}

Uma vez construído e apresentado o artefato, Dresch, Lacerda e Antunes Jr. (2015) sugerem a avaliação do mesmo a fim de verificar a sua utilidade, viabilidade, possibilidade de solucionar problemas, e de ser usado por demais organizações. Incluindo a empresa objeto de estudo, esta avaliação foi conduzida por meio de questionário e entrevista a dez microempresas localizadas na cidade de São Leopoldo, cinco do ramo de serviços, três do ramo comercial e duas do ramo industrial. O intuito é de apresentar problemas comuns e pontos de semelhança passíveis de serem solucionados a partir das ideias propostas no modelo e, de igual forma, a suscetível generalização a uma classe de problemas, como sugerido pelo método.

O questionário foi construído com base nos elementos e aspectos abordados na construção do modelo MOm, constituindo-se de oito questões, três de múltipla escolha, uma da escala de avaliação e quatro dissertativas. Todos os questionários foram respondidos por sócios das empresas e, das dez avaliadas, três localizam-se em mais de uma cidade. São empresas formadas por cônjuges, pessoas com algum laço de parentesco ou colegas de profissão.

A maioria dos empreendedores foi funcionário durante algum tempo em empresas onde realizavam a mesma atividade e, posteriormente, pelo conhecimento adquirido, constituíram a própria empresa. O Quadro 5 apresenta as empresas avaliadas, respectivos ramos de atuação, pontos considerados mais importantes para o negócio e as maiores dificuldades enfrentadas.

Quadro 5 - Empresas Avaliadas

\begin{tabular}{|c|c|c|c|c|c|}
\hline & Atividade & Ramo & Localização & Pontos Importantes & Dificuldades \\
\hline 1 & Imunizadora & Serviços & São Leopoldo & Qualidade e divulgação & $\begin{array}{c}\text { Controle financeiro e } \\
\text { concorrência }\end{array}$ \\
\hline 2 & $\begin{array}{l}\text { Estúdio de } \\
\text { fotografia }\end{array}$ & Serviços & São Leopoldo & Qualidade & \\
\hline 3 & Papelaria & Comercial & São Leopoldo & $\begin{array}{c}\text { Diversidade de } \\
\text { mercadorias }\end{array}$ & $\begin{array}{c}\text { Baixa venda e controle dos } \\
\text { gastos }\end{array}$ \\
\hline 4 & Odontologia & Serviços & São Leopoldo & Qualidade e divulgação & Construção do consultório \\
\hline 5 & Lavanderia & Serviços & São Leopoldo & $\begin{array}{c}\text { Controle financeiro e } \\
\text { qualidade }\end{array}$ & $\begin{array}{c}\text { Legislação trabalhista e } \\
\text { crise }\end{array}$ \\
\hline 6 & Doces Gourmet & Comercial & São Leopoldo & Padronização e & Férias na universidade \\
\hline
\end{tabular}




\begin{tabular}{|c|c|c|c|c|c|}
\hline & Atividade & Ramo & Localização & Pontos Importantes & Dificuldades \\
\hline & & & +1 & marketing & \\
\hline 7 & Especiarias & Industrial & $\begin{array}{l}\text { São Leopoldo } \\
+1\end{array}$ & Plano de negócios & Controle dos gastos \\
\hline 8 & Floricultura & Comercial & São Leopoldo & Clientes & $\begin{array}{c}\text { Conquista de clientes e } \\
\text { concorrência }\end{array}$ \\
\hline 9 & $\begin{array}{l}\text { Chaves e } \\
\text { carimbos }\end{array}$ & Serviços & São Leopoldo & Agilidade e qualidade & Rapidez do processo \\
\hline 10 & Ourivesaria & Industrial & $\begin{array}{l}\text { São Leopoldo } \\
+2\end{array}$ & $\begin{array}{l}\text { Qualidade e } \\
\text { atendimento }\end{array}$ & Impostos e crise no país \\
\hline
\end{tabular}

Fonte: Elaborado pelos autores com base nas entrevistas.

Dos pontos mais importantes, destacam-se a qualidade nos serviços prestados, seguido pela estratégia de divulgação e, dentre as maiores dificuldades enfrentadas, o controle financeiro e a crise econômica do país. A mais antiga das empresas é o estúdio de fotografia com trinta e oito anos de mercado e a mais nova, com três anos de mercado, a de doces gourmet.

Para a questão de avaliação consoante o grau de importância dos itens abordados no modelo MOm, as empresas possuíam valores na escala de 1 a 10, apresentados no Quadro 6. Segundo Llauradó (2015), a categoria para esse tipo de escala, independentemente do nível usado, mostra a importância e a avaliação que os entrevistados possuem sobre os itens.

Quadro 6 - Grau de Importância dos Itens Abordados no Modelo MOm

\begin{tabular}{|c|c|c|c|c|c|c|c|c|c|c|c|}
\hline Aspetos | Empresas & $\mathbf{1}$ & $\mathbf{2}$ & $\mathbf{3}$ & $\mathbf{4}$ & $\mathbf{5}$ & $\mathbf{6}$ & $\mathbf{7}$ & $\mathbf{8}$ & $\mathbf{9}$ & $\mathbf{1 0}$ & Média \\
\hline Definir missão e visão & 7 & 8 & 7 & 10 & 10 & 8 & 10 & 9 & 7 & 8 & 8,4 \\
\hline Definir valores & 7 & 8 & 9 & 10 & 9 & 10 & 9 & 9 & 7 & 9 & 8,7 \\
\hline Identificar forças e fraquezas & 6 & 7 & 7 & 10 & 9 & 10 & 7 & 8 & 7 & 8 & 7,9 \\
\hline Identificar oportunidades e ameaças & 6 & 7 & 7 & 8 & 8 & 10 & 7 & 9 & 6 & 8 & 7,6 \\
\hline Definir a estrutura & 8 & 10 & 1 & 9 & 7 & 8 & 6 & 4 & 3 & 9 & 6,5 \\
\hline Oferecer preços mais baixos & 2 & 3 & 8 & 6 & 1 & 5 & 5 & 7 & 1 & 6 & 4,4 \\
\hline Qualidade nos serviços prestados & 10 & 10 & 10 & 10 & 10 & 10 & 8 & 10 & 10 & 10 & 9,8 \\
\hline Assistência técnica & 10 & 5 & 1 & 10 & 3 & 1 & 4 & 5 & 10 & 9 & 5,8 \\
\hline Políticas de fidelização & 8 & 3 & 6 & 10 & 7 & 5 & 8 & 4 & 6 & 10 & 6,7 \\
\hline Estratégias para divulgar o serviço & 10 & 6 & 5 & 9 & 10 & 10 & 8 & 8 & 5 & 8 & 7,9 \\
\hline Dono/sócio trabalhar na empresa & 10 & 10 & 10 & 10 & 10 & 10 & 5 & 10 & 10 & 10 & 9,5 \\
\hline Diferenciar custos e despesas & 6 & 7 & 5 & 10 & 9 & 6 & 8 & 7 & 6 & 10 & 7,4 \\
\hline Separar salário dos sócios do lucro & 7 & 7 & 2 & 6 & 9 & 6 & 4 & 7 & 6 & 10 & 6,4 \\
\hline
\end{tabular}

Fonte: Elaborado pelos autores.

O Quadro 6 pode ser resumido no Gráfico 1, onde, de acordo a pontuação atribuída, a qualidade nos serviços é o ponto mais importante, com uma média de 9,8. Independentemente do ramo e atividade exercida, a qualidade é crucial para a satisfação dos clientes. Gomes (2014) diz que um produto ou serviço tem qualidade quando atende as necessidades dos consumidores. 
Gráfico 1 - Grau de Importância dos Itens do Quadro 6

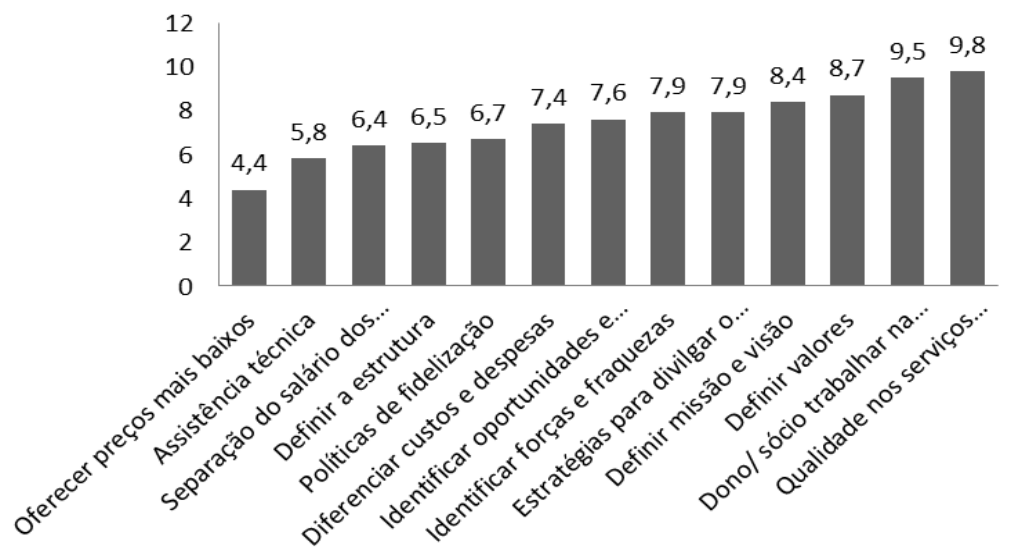

Fonte: Elaborado pelos autores.

Seguidamente à qualidade, com média 9,5, está a importância do dono ou sócio trabalhar na empresa, pois para além de serem microempresas de carácter familiar, é menos dispendioso e o conhecimento operacional está na mão dos mesmos. Segundo Coldibeli (2014), quase metade das empresas brasileiras funcionam sem funcionários porque os empreendedores alegam que o custo da contratação é elevado. Segundo o sócio da imunizadora, quando se sabe fazer as coisas e se tem alguém de confiança para ajudar, contratar mais pessoas torna-se um gasto e a boa execução do serviço é comprometida. O terceiro fator de maior importância é a definição dos valores, com 8,7, que precede a definição da missão e da visão, com 8,4.

O item praticamente descartado da lista é a oferta de baixos preços, com 4,4, o que faz algum sentido pois o mais importante dos itens é a qualidade e, quando se prima por esta tem-se preços ao seu nível. A oferta por menores preços, apesar de ser uma vantagem perante a concorrência, às vezes obriga a alterar elementos fundamentais para o sucesso do produto ou serviço. Seguidamente, apesar de ser um fator muito observado pelos clientes, obteve-se a assistência técnica, com 5,8, pois a maioria das empresas avaliadas não disponibilizam deste serviço, optando por cobrar quando o produto ou serviço apresentar alguma anomalia.

O terceiro item menos importante para os avaliados é a separação do salário do dono do lucro da empresa, sendo que apenas duas responderam que este deve ser extraído do pró-labore, ser previamente estipulado e condizer com o trabalho realizado. As demais dizem que do que é faturado no mês, extrai-se o necessário para o abastecimento de novos materiais para revenda, fabricação do produto ou realização do serviço, manutenção da empresa e pagamento de contas. O que sobra, dependendo dos casos, é repartido entre os sócios ou serve para uso pessoal.

Segundo o sócio da papelaria, que ganha do que vende, quando a venda é baixa pouco sobra para pagar as contar, repor o material e ainda manter a família. Neste caso, não há um salário definido, porém, duas empresas alegam atribuir um valor aleatório mensalmente para reservar caso algum imprevisto aconteça. Andrade (2016) afirma que a dificuldade que o microempresário tem em distinguir as despesas pessoais das da empresa traz consigo muitos problemas que até podem implicar em falência. Os demais itens, com 7,9 a identificação de forças e fraquezas e as estratégias para divulgar o serviço, 7,6 a identificação de oportunidades e ameaças, 7,4 diferenciar custos e despesas, 6,7 políticas de fidelização e, 6,5 a definição da estrutura, ficaram com uma pontuação intermédia. Alguns itens são tidos como desnecessários para o momento do negócio e outros são desconhecidos pelos empreendedores.

\section{Conclusão}

Vários são os modelos de gestão disponibilizados pela literatura para empresas em geral, bem como trabalhos que retratam os principais problemas enfrentados pelas microempresas. Grande parte destas empresas surgem levando em consideração a experiência operacional dos seus fundadores sem um planejamento das reais necessidades do negócio. O fundamental é, frequentemente, ter um negócio sem considerar um estudo de como torná-lo viável, em que as decisões são tomadas consoante a conveniência de quem o gere. (MEDEIROS, 2019; SENA, 2016). 
Alinhada a esta necessidade e pela ausência de modelos que contemplem todos os aspetos necessários para a empresa objeto de estudo, é proposto o Modelo Organizacional para a microempresa segundo o roteiro proposto pelo método da Design Science Research. Para tanto, fez-se necessário o mapeamento do estado atual para identificar as principais dificuldades e construir o artefato com elementos capazes de suprir os problemas apresentados.

O modelo foi avaliado por meio de questionário e entrevista, onde fica evidente que, são empresas de carácter familiar, estabelecem-se, preferencialmente, em um nicho de cidade e cujos problemas são similares aos da empresa em estudo. Deste modo, o modelo organizacional torna-se útil com a apresentação de itens cruciais para melhorar a gestão da empresa.

O alcance dos objetivos resultou em um modelo de possível resolução de problemas, e de passível generalização a uma classe de problemas. Assim, o presente artigo contribui com os estudos com a apresentação e desdobramento de quatro pontos, apresentados no modelo MOm, Modelo Organizacional para a microempresa, nomeadamente defina a estratégia, estabeleça a estrutura, promova o negócio e conheça os gastos, que apesar de ignorados, são essenciais para o negócio. Cientificamente, o rigor na aplicação do método da Design Science Research a partir de modelos de gestão considerados tradicionais, apresentou um modelo novo e específico para a realidade das microempresas, que muitas vezes apresentam dificuldades para utilização dos modelos mais robustos e tradicionais.

A não aplicação do modelo na empresa em estudo representa uma limitação visto que não permite comprovação prática da sua efetividade, do mesmo modo que a avaliação por meio de questionário e entrevista não mensura o quão bom, realmente, o modelo é ou tem a ser melhorado. Debois (2017) refere ainda que a avaliação por meio de questionário apenas traduz o pensamento das pessoas avaliadas, visto que impossibilita mensurar o quão aceitável e bom na prática seria a aplicação do modelo.

Para trabalhos futuros, a definição de um sistema de custeio para microempresas prestadoras de serviços é uma oportunidade, pois grande parte dos estudos dirigem seus esforços ao ramo industrial. Outro desafio é a aplicação do MOm em um contexto empresarial para comprovar a sua funcionalidade como modelo organizacional.

\section{REFERÊNCIAS}

ALVES, Izabela Ferreira. Entenda a diferença entre pro labore e distribuição de lucros. 2012. Disponível em:

$<$ https://www.google.com.br/url?sa=t\&rct=j\&q=\&esrc=s\&source=web\&cd=8\&cad=rja\&uact=8\&ved=0ahUK EwjCh8fwo6XWAhWID5AKHTK5C6cQFghPMAc\&url=https\%3A\%2F\%2Feconomia.uol.com.br\%2Fnotici as $\% 2$ Fredacao $\% 2 \mathrm{~F} 2012 \% 2 \mathrm{~F} 04 \% 2 \mathrm{~F} 03 \% 2 \mathrm{Fentenda-a}$-diferenca-entre-pro-labore-e-distribuica $>$. Acesso em: 20 set. 2017.

ANDRADE, Marcio Roberto. Despesas pessoais x despesas da empresa: uma separação necessária. 2016. Disponível em: <https://blog.contaazul.com/despesas-pessoais-X-despesas-da-empresa-uma-separacaonecessaria/>. Acesso em: 5 nov. 2017.

BICHO, Leandro; BAPTISTA, Susana. Modelo de Porter e análise SWOT: estratégias de negócio. Instituto Politécnico de Coimbra, [s. 1.], p. 1-18, 2006.

BORNIA, Antonio Cezar. Análise Gerencial dos Custos. 3ª ed. São Paulo: Atlas S.A, 2010.

BRAGA, Antonio. As cinco forças de Porter. 2013. Disponível em: $<$ http:/www.administradores.com.br/artigos/marketing/as-cinco-forcas-de-porter/73859/>. Acesso em: 30 maio. 2017.

BRAVO, Flávia Pinto; BILANGIERI, Priscila Neves. A importância da coordenação lateral de processos em organizações. Encontro Nacional de Engenharia de Produção, [s. 1.], p. 1-8, 2006.

BRUGNOLO FILHO, Marino; LUDOVICO, Nelson (Org.). Gestão estratégica de negócios. 1. ed. São Paulo: Saraiva Educação, 2018.

CARLA, Monise. As 5 forças de Porter. 2013. Disponível em: <http://www.blogdaqualidade.com.br/as-5- 
forcas-de-porter/>. Acesso em: 30 maio. 2017.

CARVALHO, Géssica Rodrigues et al. Sistemas de recompensa e suas influências na motivação dos funcionários: estudo em uma cooperativa capixaba. In: SIMPÓSIO DE EXCELÊNCIA EM GESTÃO E TECNOLOGIA 2012, Anais... [s.1.]: SEGeT, 2012. p. 1-13.

CASAROTTO, Camila. SWOT. 2016. Disponível em: <https://marketingdeconteudo.com/como-fazer-umaanalise-swot/>. Acesso em: 25 set. 2017.

CHIAVENATO, Idalberto; SAPIRO, Arão. Planejamento estratégico - fundamentos e aplicações. $2^{\mathrm{a}}$ ed. Rio de Janeiro: Elsevier, 2009.

COLDIBELI, Larissa. Metade das empresas não tem empregados; donos improvisam no dia a dia. 2014. Disponível em: <https:/economia.uol.com.br/empreendedorismo/noticias/redacao/2014/10/23/49-dasempresas-nao-tem-funcionarios-empresarios-contam-sua-rotina.htm>. Acesso em: 5 nov. 2017.

CRAIG, Justin B. L.; MOORES, Ken. Balanced Scorecards to drive the strategic planning of family firms. Family Business Review, [s. 1.], v. 18, n. 2, p. 105-122, 2005.

DAGOSTIM, Salézio. Fundamentos da contabilidade geral. Porto Alegre: EBRACON, 2010.

DEBOIS, Stefan. 9 vantagens e desvantagens dos questionários. 2017. Disponível em: $<$ https://surveyanyplace.com/pt/9-vantagens-e-desvantagens-dos-questionarios/>. Acesso em: 24 jun. 2019.

DORNELAS, José et al. Plano de negócios com o Modelo Canvas: guia prático de avaliação de ideias de negócio a partir de exemplos. 1. ed. Rio de Janeiro: LTC - Livro, 2015.

DRESCH, Aline; LACERDA, Daniel Pacheco; ANTUNES JÚNIOR, José Antonio Valle. Design Science Research: método de pesquisa para avanço da ciência e tecnologia. 1. ed. Porto Alegre: Bookman, 2015.

ELAINA, Jeniffer. As estratégia genéricas de Michael Porter. 2012. Disponível em: <https://www.portalgestao.com/artigos/6710-as-estratégias-genéricas-de-michael-porter.html>. Acesso em: 10 set. 2017.

FIDDLER, Bill. Strategic planning and your business model. Kitchen \& Bath Design News, [s. 1.], p. 46-48, 2007.

FREITAS, Cristiano. Remuneração dos sócios: saiba como os proprietários são remunerados. 2018. Disponível em: <https://syhus.com.br/2018/07/26/remuneracao-dos-socios-saiba-como-os-proprietarios-saoremunerados/>. Acesso em: 25 maio. 2020.

GABRIEL, Maurício. As forças competitivas, as estratégias genéricas e a cadeia de valor de Michael Porter. 2016. Disponível em: <http://www.administradores.com.br/artigos/academico/as-forcas-competitivasas-estrategias-genericas-e-a-cadeia-de-valor-de-michael-porter/98306/> . Acesso em: 28 maio. 2017.

GALBRAITH, Jay; DOWNEY, Diane; KATES, Amy. Projeto de organizações dinâmicas: um guia prático para líderes de todos os níveis. 1. ed. Porto Alegre: Bookman, 2011.

GOMES, Isabela Motta. Como elaborar um plano de marketing. SEBRAE, Belo Horizonte - MG, p. $91,2013$.

GOMES, João Luiz Corrêa. Qualidade em serviços. 2014. Disponível em: $<$ https://www.administradores.com.br/artigos/negocios/qualidade-em-servicos/81805/>. Acesso em: 5 nov. 2017.

HARPER, Stephen C. In management models, it's all mental. ISE Magazine, [s. 1.], p. 1-7, 2016.

HERRERA, Wagner. Proposição de valor. 2008. Disponível em: <http://www.portaldomarketing.com.br/Artigos1/Proposicao_de_valor.htm>. Acesso em: 23 out. 2017.

KAPLAN, Robert S.; NORTON, David P. The office of strategy management. Harvard Business Review, [s. 1.], v. 83, n. 10, p. 1-9, 2005. 
LEITE, João Batista Diniz; PORSSE, Melody De Campos Soares. Competição baseada em competências e aprendizagem organizacional: em busca da vantagem competitiva. Revista de Administração Contemporânea - RAC, [s. 1.], v. 7, p. 121-141, 2003.

LLAURADÓ, Oriol. Escala de Likert: o que é e como utilizá-la. 2015. Disponível em: <c:\%5CUsers\%5CPublic\%5CDocuments\%5CDocuments\%5CUNISINOS\%5CArtigo\%5CEscala de Likert O qué é e como utilizá-la.html>. Acesso em: 22 nov. 2017.

LOBRIGATTI, Luis Alberto Fernandes. Custos na prestação de serviços. SEBRAE, São Paulo, p. 18, 2004.

LOGUlHO, Flavio. Custos, despesas e perdas: qual a diferença? 2012. Disponível em: $<$ http://controlefinanceiro.granatum.com.br/dicas/custos-despesas-e-perdas-qual-a-diferenca/>. Acesso em: 26 out. 2017.

MARCONDES, José Sérgio. Estratégia organizacional: Conceito. O que é? Definição, origem. 2015. Disponível em: <http://www.gestaodesegurancaprivada.com.br/estrategia-organizacional-conceito/>. Acesso em: 12 jun. 2017.

MARTINS, Isaac. Telemarketing, você sabe o que é? 2016. Disponível em: $<$ http://institutoim.com.br/telemarketing-voce-sabe-o-que-e/>. Acesso em: 5 out. 2017.

MEDEIROS, Larissa. 7 maiores dificuldades das micro e pequenas empresas e como superá-las. 2019. Disponível em: $<$ https://blog.vhsys.com.br/principais-dificuldades-das-micros-e-pequenas-empresas/>. Acesso em: 25 maio. 2020

MINTZBERG, Henry; QUIM, James Brian. O Processo da estratégia. 3. ed. Porto Alegre: Bookman, 2001.

OSTERWALDER, Alexander; PIGNEUR, Yves. Business model generatiom: inovação em modelo de negócios. 1. ed. Rio de Janeiro: Alta Books, 2011.

PAULA, Gilles B. De. Missão, visão e valores. 2015. Disponível em: $<$ https://www.treasy.com.br/blog/missao-visao-e-valores>. Acesso em: 25 set. 2017.

PORTER, Michael E. Vantagem competitiva: criando e sustentando um desempenho superior. Rio de Janeiro: Elsevier, 1989.

PRATES, Wlademir Ribeiro. Estratégias competitivas genéricas de Porter. 2015. Disponível em: $<$ http://www.adminconcursos.com.br/2015/01/estrategias-competitivas-genericas-de.html $>$. Acesso em: 23 out. 2017.

RAYOL, Marcus Kleber Bentes; MOREIRA, Heber Lavor. A importância do plano de negócio para o sucesso do empreendimento. 2007. 20 f. Trabalho de Conclusão de Curso (Bacharel em Ciências Contábeis), Universidade Federal do Pará (UFPA), Pará, 2007.

REIS, Izabela. Empreendedorismo: a importância do plano de negócio. 2013. Disponível em: $<$ http://www.implantandomarketing.com/empreendedorismo-a-importancia-do-plano-de-negocios/>. Acesso em: 23 out. 2017.

SCHIER, Carlos Ubiratan da Costa. Gestão de custos. 1. ed. Curitiba: InterSaberes, 2013.

SENA, Nara Moura De. A importância das pessoas nas organizações. 2014. Disponível em: $<$ http://www.administradores.com.br/artigos/negocios/a-importancia-das-pessoas-nas-organizacoes/76252/>. Acesso em: 12 jun. 2017.

SENA, Jeferson. Reestruturação organizacional para pequenas e médias empresas - parte 1. 2016. Disponível em: $<$ https://ninho.biz/blog/organizacao-empresarial/reestruturacao-organizacional-para-pequenase-medias-empresas--parte-1/>.

VIVAS, Lethicia Mallet; LIPPI, Maria Clara; SILVA, Guido Vaz. Métodos para projeto organizacional: uma revisão na literatura. In: XXXIII ENCONTRO NACIONAL DE ENGENHARIA DE PRODUÇÃO 2013, 
Anais... Salvador: Enegep, 2013. p. 1-15

XAVIER, Clayton Fernando. Importância da gestão estratégica de pessoas nas empresas. 2011. Disponível em: <http://www.administradores.com.br/artigos/marketing/a-importancia-da-gestao-estrategicade-pessoas-nas-empresas/55500/>. Acesso em: 13 jun. 2017. 